\title{
Methodical approach to determination of costs at the initial stages of the project research of gas-supply systems
}

\author{
Ariadna Kirillova $^{1 *}$ and Anna Gorelova ${ }^{2}$ \\ ${ }^{1}$ Moscow State University of Civil Engineering, Yaroslavskoe shosse, 26, Moscow, 129337, Russia \\ ${ }^{2}$ LLC "Gazprom project", 142702, 23, Vokzalnaya str., Vidnoe, Moscow oblast, Russia.
}

\begin{abstract}
The article deals with topical issues at the pre-investment stage of project design to justify decisions on the feasibility of further investment and the transition to the next stage of design - the development of project documentation. At the pre-project stage, there is often a situation when the parameters of structures have not yet been determined, and capital investments must be evaluated. Methodological approaches to determining the cost of gasification facilities and the estimated model of cost calculations at the stage of investment justification with the help of enlarged indicators that improve the accuracy and validity of calculations at the stage of pre-design studies are substantiated. It is shown that the enlarged indicators used at the stage of investment justification form the regulatory basis for determining the cost of gasification facilities, for estimating capital costs, as well as for evaluating the effectiveness of investments in the selection of project options. The object of the study adopted electrically welded steel pipes and polyethylene pipes for gas pipelines. Evaluation and forecasting of the cost of gas distribution systems in the article are proposed using regression models depending on time and diameter of the pipe. The regression dependences of the cost of steel and polyethylene pipes of all standard sizes and confidence intervals for the cost of pipes allow to estimate also possible errors of the forecast cost estimation.
\end{abstract}

\section{Introduction}

The development of the construction of line-extended real estate is an important direction of the state economic policy in Russia. According to the Federal target program "Sustainable development of rural areas for 2014-2017 and for the period until 2020", it is necessary to increase the level of gasification of residential buildings in rural areas through the introduction of gas distribution networks. [1]

With the transition to a market economy, changes in price and tax conditions, the development of inflation, the use of the old regulatory framework has led to significant distortions in the valuation of capital investments. There was a need to improve the

\footnotetext{
${ }^{*}$ Corresponding author: kirillova_an@mail.ru
} 
methods of formation of specific cost and natural indicators to improve the validity of predesign solutions and capital expenditure planning. Investors, developers and customers of investment projects plan investments, mainly on the basis of financial opportunities, without paying due attention to the issues of justification of the volume of capital investments and their rational distribution in time as part of promising and current investment programs. [2-5]

Effective investment management is linked to the problem of cost estimation. In some cases, the organization does not have project documentation for the calculations, and the tender documentation does not contain complete information about the resource requirements. Organizations have to use their sources of information (consolidated figures, objects-analogues, statistics, information technology) to provide calculations. At the preproject stage, there is often a situation when the parameters of structures have not yet been determined, and capital investments must be evaluated. This is especially important in the design of autonomous gas supply systems and justification of alternative fuels. At the same time, access to data on analogous objects can be limited, there are no normative resource and technological models, there is no great choice in making an informed design decision. [6-10]

Cost optimization at the initial stages of designing gasification systems requires an assessment of capital investments using consolidated indicators that take into account the risks caused by the uncertainty of economic standards and other data. Probabilistic risk assessment in dynamics will significantly improve the validity of decisions taken at the initial stage of project research, and improve the quality of documentation. [4, 6, 11-16]

Linearly extended objects of gasification are referred to as real estate objects, as these facilities are firmly connected with the land and their movement is impossible without disproportionate damage.

Linearly extended objects are divided into:

a) linear part of pipelines:

1) gas pipelines;

2) oil pipelines.

b) highways, railways, power lines and others.

The linear part of the pipeline is a complex of facilities included in the pipeline, shut off valves, anti-corrosion protection system, communication system and automation, crossings (water, through highways, railways), nodes start and receive treatment and diagnostic devices.

\section{Object of the study}

Extremely important for the linear-extended objects is the development rationale of the construction costs of transitions of these structures through artificial obstacles (rivers, roads, transmission lines), as their costs in the estimated cost of construction is very significant. Construction of crossings over rivers on the basis of directional drilling is quite expensive, however, given the significantly shorter duration of laying and higher reliability of this method is considered to be more effective.

Linear objects have a long length and can cross a significant number of land plots with different owners, so there is a problem of registration of rights to land plots, since lease, easement, purchase of built-up land can be made only with the consent of the owner of the land.

The object of the study adopted electrically welded steel pipes (GOST 10704-91, GOST 10705-80) with the following diameters: $57 \times 3.5 ; 76 \times 3.5 ; 89 \times 4 ; 108 \times 4 ; 114 \times 4 ; 159 \times 4.5$; $219 \times 6 ; 273 \times 5 ; 325 \times 6 ; 426 \times 6$ and $530 \times 8$ and polyethylene pipes for gas pipelines (GOST R 
50838 2009, PE 100, SDR11), diameter (wall thickness) $63 \times 5.8 ; 90 \times 8.2 ; 110 \times 10$; $160 \times 14.6 ; 225 \times 20.5 ; 315 \times 28.6 ; 400 \times 36.3$, used in the gasification of Russian regions.

To determine and predict the cost of gas distribution systems, the analysis of one of the components of this cost was carried out - the analysis of the dynamics of changes in the cost of the linear part of pipelines used at gasification facilities, performed using state and industry estimates. In order to improve the accuracy of current and projected changes in cost over time, an evaluation model was developed to predict the cost of steel and polyethylene gas pipelines based on regression analysis.

The regression equation specifies the dependence of the conditional expectation of a random variable of response $\mathrm{Y}$ from a vector of factors $\mathrm{X}=\left(\mathrm{X}_{1} \ldots \mathrm{X}_{\mathrm{k}}\right)$. To find the regression dependence, you need: 1) to find the regression equation, 2) to build estimates of unknown parameters of this equation, and 3) to test the statistical hypothesis about the significance of regression.

The linear regression equation of gas pipes has the following form:

$$
y=A_{0}(\mathrm{~d})+A_{l}(\mathrm{~d}) t,
$$

where:

$A_{0}(\mathrm{~d})$ and $A_{I}(\mathrm{~d})$ - coefficients that depend on the size of the pipes d;

$t$ - time.

Analysis of 18 regression equations defined for all sizes of gas pipelines used at gasification facilities allows us to give suggestions on generalizing regression models for estimating and forecasting the cost of gas distribution systems. Based on the analysis of the observation field, the following regression equations were considered:

$$
\begin{gathered}
\mathrm{y}_{i j}{ }^{*}=\mathrm{a}_{00}+\mathrm{a}_{10} \mathrm{t}_{i}+\mathrm{a}_{01} \mathrm{~d}_{j}+\mathrm{a}_{11} \mathrm{t}_{i} d_{j} \\
\mathrm{y}_{i j}{ }^{*}=\mathrm{a}_{00}+\mathrm{a}_{10} \mathrm{t}_{i}+\mathrm{a}_{01} \mathrm{~d}_{j}+\mathrm{a}_{02} \mathrm{~d}_{j}{ }^{2}+\mathrm{a}_{11} \mathrm{t}_{j} \mathrm{~d}_{j}+\mathrm{a}_{12} \mathrm{t}_{j} \mathrm{~d}_{j}{ }^{2} \\
\mathrm{y}_{i j}{ }^{*}=\mathrm{a}_{00}+\mathrm{a}_{10} \mathrm{t}_{i}+\mathrm{a}_{01} \mathrm{~d}_{j}+\mathrm{a}_{02} \mathrm{~d}_{j}{ }^{2}+\mathrm{a}_{11} \mathrm{t}_{i} \mathrm{~d}+\mathrm{a}_{12} \mathrm{t}_{i} \mathrm{~d}_{j}{ }^{2}+\mathrm{a}_{03} \mathrm{~d}_{j}{ }^{3}+\mathrm{a}_{13} \mathrm{t}_{i} \mathrm{~d}_{j}{ }^{3}
\end{gathered}
$$

where: $\mathrm{y}_{i j}{ }^{*}$ - the dependence of the value of the pipe diameter and time.

The coefficients $a_{00} \ldots a_{13}$ are determined from the condition of the minimum variance of deviations $\mathrm{y}_{i j}{ }^{*}$ from the sample values $\mathrm{y}_{i j}$ :

$$
\min (1 / 55) \mathrm{S}\left(\mathrm{a}_{00}, \ldots, \mathrm{a}_{11}\right)=\min (1 / 55) \sum_{i j}\left(y_{i j}-y_{i j}{ }^{*}\right)^{2},
$$

After calculating the gradient of the function $\mathrm{S}$ and equating it with zero, we obtain the so-called system of normal equations, solving which we find the desired values of the regression coefficients $\mathrm{a}_{00} \ldots \mathrm{a}_{13}$.

For a probabilistic description of cost and effect prediction errors, the variance and the mean square deviation of the formulas are determined:

$$
\sigma 2=\frac{1}{n T} \sum_{i=1}^{T} \sum_{j=1}^{n}\left[S\left(t_{i}, D_{j}\right)-y_{0}\left(D_{j}\right)-t_{i} y_{1}\left(D_{j}\right)\right]^{2},
$$

where: $n$ - number of pipe sizes;

$\mathrm{T}-$ the number of years of fixing the price of tubes;

$\mathrm{S}$ - the cost of pipes;

$\sigma^{2}-$ mean square deviation. 


\section{Basic assumptions, method and algorithm}

In order to predict changes in the cost over time for different pipe diameters in a rectangular coordinate system, correlation fields were constructed, that is, graphs where the ordinate values of the effective feature - $y$ (pipe cost), and the abscissa axis - time values $t$ (years) are postponed. Based on the correlation fields, the hypothesis (for the General population) is that the relationship between $y$ and $t$ values is linear.

The article presents the calculations of the following regression models.

1. Model of forecasting the cost of 1 ton of steel pipelines (RUB/t).

As a result of calculations for forecasting the cost of steel pipes per 1 ton, the following regression models are justified:

$$
\begin{gathered}
\mathrm{y}_{i j}{ }^{*}=29285.272+2.777 \mathrm{t}_{i}+2740.471 \mathrm{~d}_{j}-3.574 \mathrm{t}_{i} \mathrm{~d}_{j} \\
\mathrm{y}_{i j}{ }^{*}=25478.394+38.506 \mathrm{t}_{i}+11910.655 \mathrm{~d}_{j}-3636.703 \mathrm{~d}_{j}{ }^{2}-98.973 \mathrm{t}_{i} \mathrm{~d}_{j}+39.719 \mathrm{t}_{i} \mathrm{~d}_{j}{ }^{2} \\
\mathrm{y}_{i j}{ }^{*}=18309.120+499.797 \mathrm{t}_{i}+39626.472 \mathrm{~d}_{j}-29650.548 \mathrm{~d}_{j}{ }^{2}-1903.345 \mathrm{t}_{i} \mathrm{~d}_{j}+ \\
1744.312 \mathrm{t}_{i} \mathrm{~d}_{j}{ }^{2}+6655.043 \mathrm{~d}_{j}{ }^{3}-437.670 \mathrm{t}_{i} \mathrm{~d}_{j}{ }^{3}
\end{gathered}
$$

Steel lines model calculation (7), (8), (9) the accuracy of calculations is 1854.31; $1348.02 ; 1442.54$ rubles per ton. Consequently, the regression model $(8)$ is preferable when forecasting the cost of steel pipelines per ton for the future (calculation error $-4.2 \%$ ).

2. The prediction model of value $1 \mathrm{r}$. m. steel lines, RUB/r. m. Calculate the normal system of equations by Gauss method, we get the following regression models for assessing and forecasting value of steel gas mains (RUB per running meter):

$$
\begin{gathered}
\mathrm{y}_{i j}{ }^{*}=-401.964-0.963 \mathrm{t}_{i}+1424.552 \mathrm{~d}_{j}+0.852 \mathrm{t}_{i} \mathrm{~d}_{j} \\
\mathrm{y}_{i j}{ }^{*}=43.152-1.254 \mathrm{t}_{i}+352.385 \mathrm{~d}_{j}+425.189 \mathrm{~d}_{j}{ }^{2}+2.774 \mathrm{t}_{i} \mathrm{~d}_{j}-1.009 \mathrm{t}_{i} \mathrm{~d}_{j}{ }^{2} \\
\mathrm{y}_{i j}{ }^{*}=-93.975-8.735 \mathrm{t}_{i}+881.658 \mathrm{~d}_{j}-71.227 \mathrm{~d}_{j}{ }^{2}+28.323 \mathrm{t}_{i} \mathrm{~d}_{j}-23.201 \mathrm{t}_{i} \mathrm{~d}_{j}{ }^{2}+ \\
126.954 \mathrm{~d}_{j}{ }^{3}+5.418 \mathrm{t}_{i} \mathrm{~d}_{j}{ }^{3}
\end{gathered}
$$

For steel pipes according to regression models (10), (11), (12) the calculation error (12) is about $6.5 \%$ of the average cost for all sizes of pipes. Consequently, the regression model (12) is preferable in forecasting the future cost of steel pipelines per running meter.

Having calculated the system of normal equations by Gauss method in a similar way, we obtain the following regression models for estimating and forecasting the cost of polyethylene gas pipelines (RUB per running meter):

$$
\begin{gathered}
\mathrm{y}_{i j}{ }^{*}=-1367.403+13.45 \mathrm{t}_{i}+2556.871 \mathrm{~d}_{j}-16.453 \mathrm{t}_{i} \mathrm{~d}_{j} \\
\mathrm{y}_{i j}{ }^{*}=105.096-9.539 \mathrm{t}_{i}-311.381 \mathrm{~d}_{j}+1005.546 \mathrm{~d}_{j}{ }^{2}+28.69 \mathrm{t}_{i} \mathrm{~d}_{j}-15.901 \mathrm{t}_{i} \mathrm{~d}_{j}{ }^{2} \\
\mathrm{y}_{i j}{ }^{*}=224.659-20.012 \mathrm{t}_{i}-675.274 \mathrm{~d}_{j}+1301.637 \mathrm{~d}_{j}{ }^{2}+60.615 \mathrm{t}_{i} \mathrm{~d}_{j}-41.904 \mathrm{t}_{i} \mathrm{~d}_{j}{ }^{2}- \\
68.732 \mathrm{~d}_{j}{ }^{3}+6.04 \mathrm{t}_{i} \mathrm{~d}_{j}{ }^{3}
\end{gathered}
$$

For polyethylene pipelines for regression models is the calculation of (13), (14), (15) the accuracy of calculations according to the latest models is on the order of $1.75 \%$ of the average cost across all sizes of pipe. Therefore, the regression model (15) is preferable when forecasting the cost of polyethylene pipelines for the future per running meter.

The proposed approach allows to analyze the developed project documentation and investment decisions, to choose the best quality and advanced solutions, to include these 
solutions in the developed regression models for each component of the cost in order to determine the current and projected cost of gas distribution systems when including costs in the investment program.

In Figure 1 below the chart of goals and objectives determining the main directions of increasing the validity of investment decisions in gas distribution: unification of design solutions, the availability of institutional environment, financial attractiveness, ensuring the warranty and reliability of design solutions is presented. Unification of design solutions involves a comprehensive approach and interaction: the investor, the customer, the operating and design organizations to choose effective design solutions.

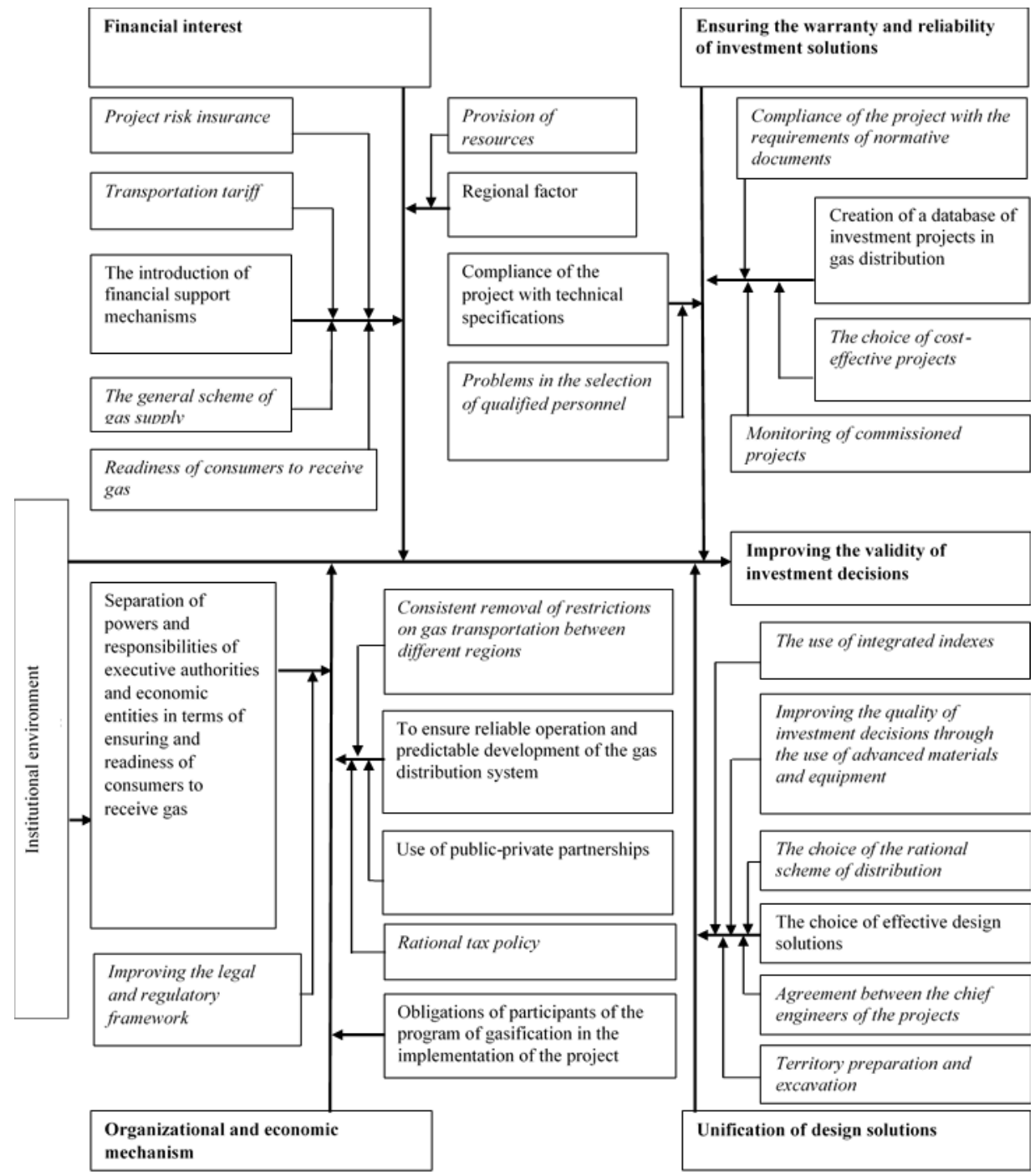

Fig. 1. Chart of goals and objectives of gas distribution systems, determining the direction of increasing the validity of investment decisions.

The basis for the production, transportation and distribution of gas is an institutional environment characterized by a set of the following rules: the need for a clear division of powers and responsibilities of executive authorities and business entities in terms of ensuring and readiness of consumers to receive gas using public-private partnership 
mechanisms, financial attractiveness and support of investment projects, warranty and reliability of investment decisions.

\section{Conclusions}

The creation of a system of enlarged cost indicators is necessary in order to: ensure the possibility of determining the cost of production construction in current (forecast) prices at the initial stages of project evaluation; the ability to evaluate production facilities by the investor in the period of preparation for bidding and selection on a competitive basis of the contractor; determine the cost of construction taking into account price dynamics for comparative economic calculations and selection of the most effective projects, taking into account regional conditions and market conditions.

Substantiated methodological approaches to determining the cost of gasification facilities and the estimated model of cost calculations at the stage of investment justification with the help of enlarged indicators allow to increase the accuracy and validity of calculations at the stage of pre-design studies.

\section{References}

1. M.A. Kocheva, A.S. Antonov, S.V. Khorev, International journal of experimental education, 10-1 (2015)

2. V.P. Antipov, General schemes of gas supply and gasification of regions of the Russian Federation. Justification of indicators of estimated cost of construction of gasdistributing systems (the enlarged indicators) (Gazprom, Moscow, 2008)

3. P.G. Graboviy, S.A. Bolotin, E.A. Gusakova, A.N. Kirillova etc., Surveying: organization, examination, management (Publishing house "ASV", Moscow, 2015)

4. P.G. Graboviy, A.N. Kirillova etc., Urban governance and modernization of housing and utilities infrastructure (IA "Educator", Moscow, 2013)

5. P.G. Graboviy, N.Y. Yaskova, Finance and credit in real estate ("Prospect", Moscow, 2013)

6. A.V. Gorelova, Estimation of cost of objects of building on pre-investment stage. The collection of materials of VII International scientific-practical conference ("MGSU", Moscow, 2015)

7. A.V. Gorelova, Problems of the economy and management of the oil and gas complex, $8(2010)$

8. V.P. Dorozhkin, Construction newspaper, 2 (2010)

9. Guidelines for the implementation of pre-investment studies in Gazprom ("Gazprom", Moscow, 2009)

10. R.V. Kondratiev, M.A. Kocheva, Modern high-tech technology, 8-2 (2013)

11. A.M. Karasevich, N.M. Storonsky, V.P. Antipov etc., Consolidated comprehensive prices for construction of objects of gasification of the Russian regions. Development estimates 2005 ("Promgaz", Moscow, 2005)

12. E.R. Stavrovskiy, A.V. Gorelov, Science and technology in the gas industry, 1 (2015)

13. Methodology for assessing the economic efficiency of investment projects in the form of capital investments ("Agency of direct Investments", "Gazprom", 2009)

14. The concept of participation of "Gazprom" in gasification of regions of Russia ("Gazprom", Moscow, 2009) 
15. SN 42 - 101 - 2003 - General provisions for the design and construction of gas distribution systems of metal and polyethylene pipes (Polimergaz, Moscow, 2004)

16. SP 42 - 103 - 2003 - design and construction of gas pipelines from polyethylene pipes and reconstruction of worn-out gas pipelines (Polimergaz, Moscow, 2004) 